\title{
燃料电池阴离子交换聚合物膜的研究与发展
}

严锋

苏州大学材料与化学化工学部, 苏州 215123

E-mail: fyan@suda.edu.cn

\section{Recent progress of anion exchange membranes for fuel cell applications}

Feng Yan

College of Chemistry, Chemical Engineering and Materials Science, Soochow University, Suzhou 215123, China

E-mail: fyan@ suda.edu.cn

doi: 10.1360/N972018-01278

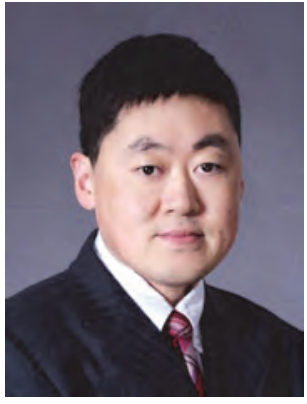

\section{严锋}

苏州大学教授, 国家杰出 青年科学基金获得者. 主 要从事聚离子液体功能 材料的设计合成及其在 能源器件、刺激响应材料 及抗菌材料等领域的研 究.
基于阴离子交换聚合物膜的碱性燃料电池具有可使用非贵金属催化剂、电极 反应速率快等优点, 受到广泛关注。阴离子交换聚合物膜是碱性电解质膜燃料电 池的核心部件, 起到传导离子和阻隔燃料的双重作用, 其性质直接决定着碱性燃 料电池的最终性能、能量效率和使用寿命, 因此受到高分子化学、材料与能源器 件领域学者的广泛关注。最近十几年，阴离子交换聚合物膜在材料的制备方法、 性能表征和应用研究方面都取得了巨大的进展. 相关领域的学者提出了一系列新 型制备阴离子交换聚合物膜的方法; 设计、合成出各种新颖的聚合物主链结构和 阳离子结构; 电极的组装工艺不断改进, 电池功率密度和稳定性不断提高. 一方 面对阴离子交换聚合物膜的降解机理、离子传导机制的理解不断深入，另一方面 对阴离子交换聚合物膜微观结构的调控方法和手段日趋精细. 因此, 阴离子交换 聚合物膜的性能, 特别是耐碱性和电导率有了极大的提高, 有力地推动了燃料电 池的发展.

为了激发社会各界对阴离子交换聚合物膜领域的兴趣，推动同行之间的学术 交流，《科学通报》特别推出了“燃料电池阴离子交换聚合物膜”专题, 特邀活跃在 科研一线的国内研究阴离子交换聚合物膜的课题组就该领域的发展前沿和热点进 行了介绍. 其中, 李南文课题组 ${ }^{[1]}$ 详细介绍了聚烯烃类阴离子交换膜的研究进展; 张所波课题组 ${ }^{[2]}$ 对胍盐阴离子交换膜研究进展进行了详尽总结并对其未来的发展 进行了展望; 贺高红、焉晓明课题组 ${ }^{[3]}$ 总结了高耐碱性阴离子交换聚合物膜的研 究进展并总结了提高膜耐碱性的方法; 相艳、卢善富课题组 ${ }^{[4]}$ 梳理了阴离子交换 聚合物膜发展中存在的关键问题, 并从链结构调控的角度提出了解决思路; 丁建 宁、林本才课题组 ${ }^{[5]}$ 介绍了基于螺环季铵盐的阴离子交换膜的制备方法及其性能; 那辉棵题组 ${ }^{[6]}$ 详细报道了多季铵基团聚芳醚酮阴离子交换膜的最新研究成果; 王 哲课题组 ${ }^{[7]}$ 对其设计的侧链有序交联型咪唑功能化阴离子交换膜结构进行了详细 介绍; 张守海课题组 ${ }^{[8]}$ 报道了季铵化杂菜联苯聚芳醚酮酮离子交换膜制备及其性 能研究.

我们衰心希望本期“燃料电池阴离子交换聚合物膜”专题能为广大读者带来一 
些新的认识和体会, 希望相关领域的学者可以更好地了解阴离子交换聚合物膜及燃料电池领域的最新进展以 及发展前沿和热点, 为我国的阴离子交换聚合物膜及燃料电池的研究注入新的活力. 在此, 对参与本专题的 所有作者、审稿人及编辑部工作人员的辛勤劳动表示衰心的感谢!

\section{参考文献}

1 Liu L, Chu X M, Li N W. Recent development in polyolefin-based anion exchange membrane for fuel cell application (in Chinese). Chin Sci Bull, 2019, 64: 123-133 [刘否, 褚晓萌, 李南文. 碱性燃料电池用聚烯烃类阴离子交换膜的研究进展. 科学通报, 2019, 64: 123-133]

2 Xue B X, Zheng J F, Zhang S B. Advances in alkaline stable guanidinium based anion exchange membranes (in Chinese). Chin Sci Bull, 2018, 63: 134-144 [薛博欣, 郑吉富, 张所波. 耐碱的胍盐阴离子交换膜研究进展. 科学通报, 2019, 64: 134-144]

3 Gao L, Wu X M, Yan X M, et al. Research progress on alkali stability of anion exchange membrane (in Chinese). Chin Sci Bull, 2019, 64: 145-152 [高莉, 吴雪梅, 焉晓明, 等. 碱性阴离子交换膜的碱稳定性. 科学通报, 2019, 64: 145-152]

4 Si J J, Lu S F, Xiang Y. Progress of polymer chain structure regulation of alkaline anion-exchange membranes for fuel cells (in Chinese). Chin Sci Bull, 2019, 64: 153-164 [司江菊, 卢善富, 相艳. 燃料电池用碱性阴离子交换膜链结构调控研究进展. 科学通报, 2019, 64: 153-164]

5 Xu F, Yuan W S, Zhu Y Y, et al. Preparation and properties of anion exchange membranes based on spirocyclic quaternary ammonium salts (in Chinese). Chin Sci Bull, 2019, 64: 165-171 [徐斐，袁文森，朱媛媛，等. 基于螺环季铵盐的阴离子交换膜的制备与性能. 科 学通报, 2019, 64: 165-171]

6 Zhao C J, Bu F Z, Na H. Preparation and properties of anion exchange membranes based on multiple quaternary ammonium groups (in Chinese). Chin Sci Bull, 2019, 64: 172-179 [赵成吉, 卜凡哲, 那辉. 侧链含多季铵基团聚芳醚酮阴离子交换膜的制备与性能. 科学 通报, 2019, 64: 172-179]

7 Du X M, Li M H, Wang Z, et al. The ordered side chain imidazole functionalized cross-linked anion exchange membrane (in Chinese). Chin Sci Bull, 2019, 64: 180-186 [杜傘明, 李铭卉, 王哲, 等. 侧链有序交联型咪唑功能化阴离子交换膜. 科学通报, 2019, 64: 180-186]

8 Zhang S H, Zhang B G, Chen Y N, et al. Preparation and properties of quaternized poly (phthalazinone ether ketone ketone) anionexchange membrane for all-vanadium redox flow battery (in Chinese). Chin Sci Bull, 2019, 64: 187-193 [张守海, 张本贵, 陈宇宁, 等. 季铵化杂荎联苯聚芳醚酮酮离子交换膜制备与性能. 科学通报, 2019, 64: 187-193] 